\title{
USING QUICKBOOKS ONLINE PLUS FOR ENHANCING LEARNING OF ERP CONCEPTS: A CASE STUDY
}

\author{
Kamal Hingorani, Alabama State University, khingorani@alasu.edu \\ Bob McNeal, Alabama State University,bobmcneal@alasu.edu
}

\begin{abstract}
This paper describes the implementation of the Global Bike Inc. ERP (Enterprise Resource Planning) configuration developed by the SAP University Alliance on QuickBooks Online Plus. QuickBooks Online Plus is the SaaS implementation of QuickBooks. Although students develop an understanding of ERP processes through the configuration exercises for SAP, some students are confused by the maze of complexity encountered when they attempt to configure and customize SAP software. Implementing ERP on QuickBooks Online helps to reinforce the concepts of ERP processes on a cloud-based software that is more intuitive and easier to use than large mainstream Enterprise Resource Planning (ERP) software. It also allows the students to configure a new company in software that is the industry standard for small businesses. The implementation of the ERP exercises on QBO Plus are also compared with the implementation on QuickBooks Accountant and on SAP.
\end{abstract}

Keywords: Information Technology (IT), SAP, QuickBooks, ERP, Student Learning, cloud-based software, SaaS

\section{INTRODUCTION}

ERP systems are the largest, most complex, and most demanding information systems implemented by firms and are the heart of Information Systems of most large and medium sized companies. ERP education has therefore become an important aspect of general information systems, business, and management curricula. Integration of ERP systems into graduate and undergraduate business courses has been widely reported (Winkelmann and Leyh, 2010). The SAP university alliance has played a major role in infusing ERP education in business schools across the nation and the world. According to the latest data, SAP University Alliances has enabled more than 3,500 educational institutions in over 113 countries to integrate the latest SAP technologies into teaching (SAP University Alliance, 2018).

SAP continues to be the leading software vendor for ERP software. According to their corporate fact sheet, SAP serves over 388,000 customers in more than 180 countries. Their customers include $92 \%$ of the Forbes Global 2000 companies and $98 \%$ of the 100 most valued brands; and produce $78 \%$ of the world's food and $82 \%$ of the world's medical devices $77 \%$ of the world's transaction revenue is recorded through an SAP system (SAP Corporate Fact Sheet, 2018).

One of the popular SAP courses developed by the SAP University Alliance is Global Bikes Inc. (GBI). This course focuses on configuring SAP for a trading goods company that procures and then sells products (SAPUAP, 2013). Although the course is taught using a hands-on approach, some of the concepts are difficult for undergraduate students to grasp. Some of the high-achieving students are able to acquire an understanding of the underlying business processes in financial accounting, procurement and fulfillment (sales). However, others are confused when faced with the complexity of configuring and customizing SAP software. The exercises for the financial accounting, procurement and sales follow the configuration exercises and are relatively easier to complete and students lose focus in the course. Previously, we reported the successful implementation of the GBI configuration on QuickBooks Accountant- the desktop version of QuickBooks (Hingorani et. al, 2015). Supplementing the business processes on a simpler software proved beneficial to students in learning the underlying business processes. QuickBooks required fewer steps for the configuration of the company and the students could focus on the business processes. 
As has been the trend in industry, most companies are moving from shrink-wrapped software to providing the software as a service. Intuit, the developer of QuickBooks, has been aggressively pushing QuickBooks Online (QBO) with great success.

\section{LITERATURE REVIEW}

The SAP UA SAP R/3 GBI case configuration manual is a copy-righted product of the SAP University Alliance. The manual covers six topics : Financial Accounting, Procurement, Fulfillment, Production, Material Planning, and Warehouse Management. Our implementation targeted only the first three phases of ERP configuration. The Financial Accounting Phase has four parts with 44 pages of documentation involving a total of 36 hands-on exercises. The Procurement Phase has four parts with 42 pages of documentation involving 26 hands-on exercises. The Fulfillment Phase has four parts with 35 pages of documentation involving 24 hands-on exercises.

QuickBooks Accountant required only four configuration exercises as listed below. These configuration exercises are on a menu driven interface that is very intuitive instead of detailed instructions that are required for configuring a company on SAP.

1. Create a New Company

2. Set-Up Bank Account

3. Add Products (Trading Goods)

4. Add Vendors and Customers

The configuration and process execution in each of the phases on SAP and QuickBooks Accountant are detailed in Table 1 below:

Table 1. GBI on SAP ERP and QuickBooks Accountant

\begin{tabular}{|l|l|l|l|}
\hline \multicolumn{1}{|c|}{ Phases on SAP } & $\begin{array}{l}\text { Configuration } \\
\text { Exercises on } \\
\text { SAP }\end{array}$ & Process Execution on SAP & \multicolumn{1}{|c|}{$\begin{array}{c}\text { Process Execution on } \\
\text { QuickBooks Accountant }\end{array}$} \\
\hline $\begin{array}{l}\text { Phase I- Financial } \\
\text { Accounting (44 } \\
\text { pages and 36 } \\
\text { exercises) }\end{array}$ & 32 & $\begin{array}{l}\text { Four exercises (4): Review } \\
\text { Accounts, Display Balances I, } \\
\text { Enter General Ledger Account } \\
\text { Postings, Display Balances II }\end{array}$ & $\begin{array}{l}\text { Four exercises (4): Add Capital } \\
\text { Stock, Buy Office Supplies, Print } \\
\text { Balance Sheet Reports }\end{array}$ \\
\hline $\begin{array}{l}\text { Phase II- } \\
\text { Procurement (42 } \\
\text { pages and 26 } \\
\text { exercises) }\end{array}$ & 21 & $\begin{array}{l}\text { Five exercises (5): Create } \\
\text { Purchase Requisition, Create } \\
\text { Purchase Order, Create Goods } \\
\text { Receipt, Receive Invoice, Pay } \\
\text { Vendor }\end{array}$ & $\begin{array}{l}\text { Six exercises (6): Create Purchase } \\
\text { Order, Receive Items, Print Inventory } \\
\text { Vendor, Pnter Invoice (Bill), Pay }\end{array}$ \\
\hline $\begin{array}{l}\text { Phase III- } \\
\text { Fulfillment (35) } \\
\text { pages and 24 } \\
\text { exercises) }\end{array}$ & 18 & $\begin{array}{l}\text { Six exercises (6): Create Sales } \\
\text { Quotation, Create Sales Order, } \\
\text { Create Outbound Delivery, Ship } \\
\text { Materials, Create Invoice, } \\
\text { Receive Payment }\end{array}$ & $\begin{array}{l}\text { Seven exercises (7): Create Sales } \\
\text { Order, Fulfill Sales Order, Create } \\
\text { Invoice, Print Inventory Valuation } \\
\text { report, Receive Payment, Print } \\
\text { Income Statement Report. }\end{array}$ \\
\hline
\end{tabular}

The ERP implementation on QuickBooks was quicker and students could focus on process execution without becoming confused with configuration as was the case with the implementation on SAP. A tutorial developed on QuickBooks Accountant was incorporated in the ERP configuration course at our university. This tutorial was found to be helpful for reinforcing the concepts of business processes and their execution in all the three phases described above. 


\section{THE MOVE TO SaAS- QUICKBOOKS ONLINE PLUS}

QuickBooks is an accounting software package designed for small and medium-sized businesses. It has a market share of around 90 percent in North America, making it one of the most powerful and long-lasting near monopolies in the business software industry (Brooks, 2018). Although QuickBooks is described as an accounting software, in many ways, the desktop version has most of the features of the financial accounting, procurement and sales processes that are available on SAP (Dignan, 2014). The business processes and nomenclature are also very similar to the ones that are used in SAP.

QuickBooks was originally developed as a desktop product but Intuit is now pushing QuickBooks Online (QBO) in the delivery model of software as a service (SaaS). With the well-documented success of Adobe in moving from selling shrink-wrapped products to offering web-based software and services, there is a business need for Intuit to focus on offering QuickBooks as SaaS. Based on the initial success of their SaaS offering, Intuit may soon stop supporting further development on the desktop version of QuickBooks.

As of January 31, 2018, there were 2.8 million QuickBooks Online subscribers, an increase of 51\% compared with the same point in time in 2017 (Intuit, 2018). There are three versions of QuickBooks Online- Simple Start is designed for microbusinesses, Essentials adds bill-paying and instant reports while Plus allows tracking of inventory and preparing 1099s for contractors. QBO Plus is provided free of charge to academic institutions through the Intuit education program. Each student is provided a free account on QBO for one year and they can create one company. A purge company feature can be used to start a new company.

Our university had already supplemented the SAP ERP configuration with a successful in-house developed configuration tutorial using the desktop version - QuickBooks Accountant but there was a need to shift to the cloud version of the software. Our Small Business Development Center, which provides support to small businesses in the state, had already switched to offering training on QuickBooks online and we could not afford to use a tool that was declining in relevance and popularity.

This semester we switched to the cloud-based version of the software- QuickBooks Online Plus. We developed a tutorial has been incorporated into a course on ERP configuration. This tutorial will supplement ERP concepts alongside the GBI configuration on SAP.

\section{QUICKBOOKS ONLINE PLUS VS QUICKBOOKS ACCOUNTANT}

There are substantial differences between QBO Plus and the QuickBooks Accountant. For example, the present version of QBO Plus does not support Sales Orders. The user has to create an estimate, which is a non-posting transaction, which is then converted to an invoice. The invoice has to substitute for a sales order (Intuit Community, 2018). Further, creating a bank account requires a real bank account; many students are not willing to share their bank information for classwork. Another issue is the lack of a Common Stock account in the default chart of accounts. Both of these issues can be solved by creating new accounts in the Chart of Accounts (COA). The differences in which SAP, QuickBooks Accountant and QuickBooks Online Plus handle the business process activities are described next.

\section{Process Activities for Financial Accounting}

The financial accounting processes for the three software offerings are compared in Table-2. There is no difference between the process in QuickBooks Accountant and QBO Plus. The screens on QBO online are on a browser and more user-friendly than the one on QuickBooks Accountant. 
Table 2. The Financial Accounting on the three software

\begin{tabular}{|l|l|l|}
\hline \multicolumn{1}{|c|}{ SAP } & \multicolumn{1}{|c|}{ QuickBooks-Desktop } & \multicolumn{1}{c|}{ QBO Plus } \\
\hline Four exercises (4): & Four exercises (4): & Four exercises (4): \\
1. Review Accounts & 1. Add Capital Stock, & 1. Add Capital Stock, \\
2. Display Balances I, & 2. Print Balance Sheet Reports & 2. Print Balance Sheet Reports \\
3. Enter General Ledger Account & 3. Buy Office Supplies, & 3. Buy Office Supplies, \\
$\begin{array}{l}\text { Postings, } \\
\text { Display Balances II }\end{array}$ & 4. Print Balance Sheet Reports & Print Balance Sheet Reports \\
\hline
\end{tabular}

\section{Process Activities for Procurement Cycle}

QBO Plus is different in the way that it implements the procurement cycle. The procurement cycle are compared in Table-3. There is no process that receives the items ordered. This has to be handled through the Create Bill process. The create bill process allows the receipt of partial orders.

Table 3. The Procurement Cycle on the three software

\begin{tabular}{|l|l|l|}
\hline SAP & QuickBooks-Desktop & QBO Plus \\
\hline 1. Create Purchase Requisition, & 1. Create Purchase Order & 1. Create Purchase Order \\
2. Create Purchase Order & 2. Receive Items & 2. Create Bills \\
3. Create Goods Receipt & 3. Enter Bill & 3. Pay Bills \\
4. Receive Invoice & 4. Pay Vendor & \\
5. Pay Vendor & & \\
\hline
\end{tabular}

\section{Process Activities for Sales (Fulfillment) Cycle}

The differences in the sales cycle process are shown in Table-4. QBO does not support sales orders and a company has to use an estimate to substitute as a sales order.

Table 4. The Sales Cycle on the three software

\begin{tabular}{|l|l|l|}
\hline SAP & QuickBooks-Desktop & QBO Plus \\
\hline 1. Create Sales Quotation & 1. Create Sales Order & 1. Create Estimate \\
2. Create Sales Order & 2. Fulfill Sales Order & 2. Create Invoice \\
3. Create Outbound Delivery & 3. Create Invoice & 3. Receive Payment, \\
4. Ship Materials & 4. Receive Payment, & \\
5. Create Invoice & & \\
6. Receive Payment & & \\
\hline
\end{tabular}

\section{CONFIGURATION ON QBO PLUS}

The configuration required for the GBI case in QBO Plus is discussed next.

\section{Company Configuration}

This is a relatively simple process in QBO Plus and requires data entries on two different screens as shown in Figure-1 and Figure-2. A user has to enter the company name, the tax form, and the industry type. A logo has also to be provided. 


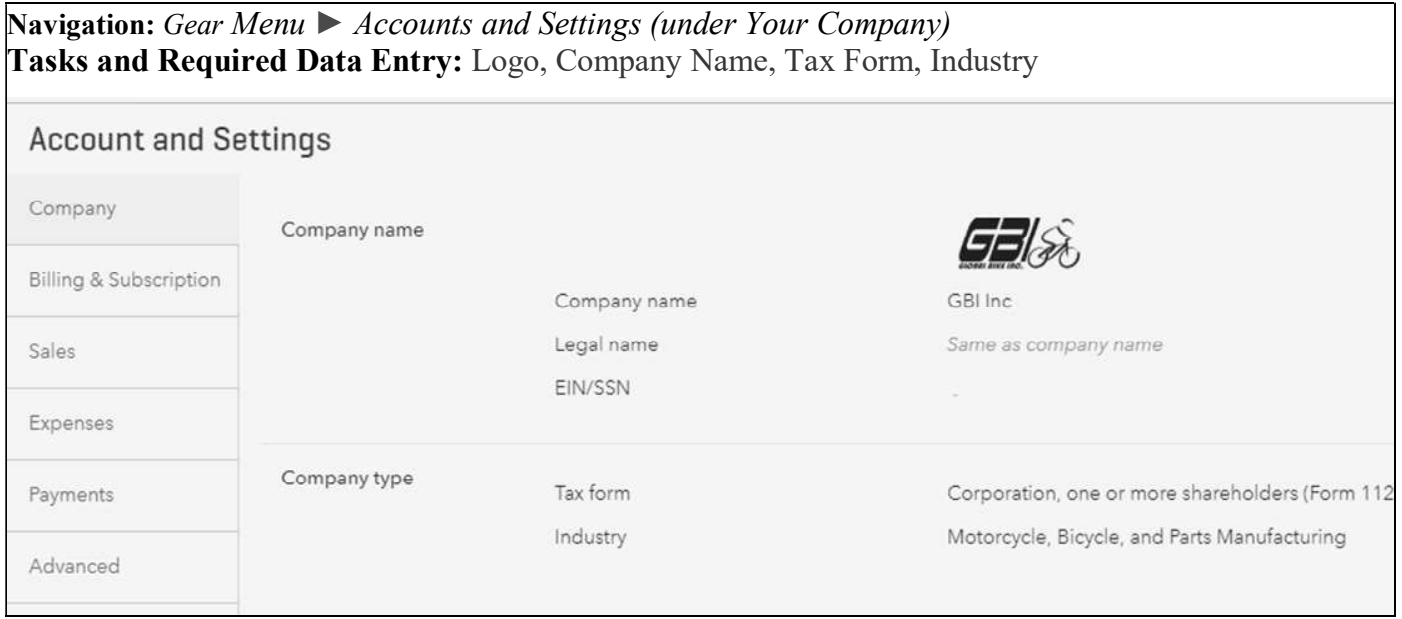

Figure 1. Configuration for Company Name, Tax Form, and Industry

The user has also to provide the billing payment terms. A simple input screen allows selection of Net 30 days for bill payment terms.

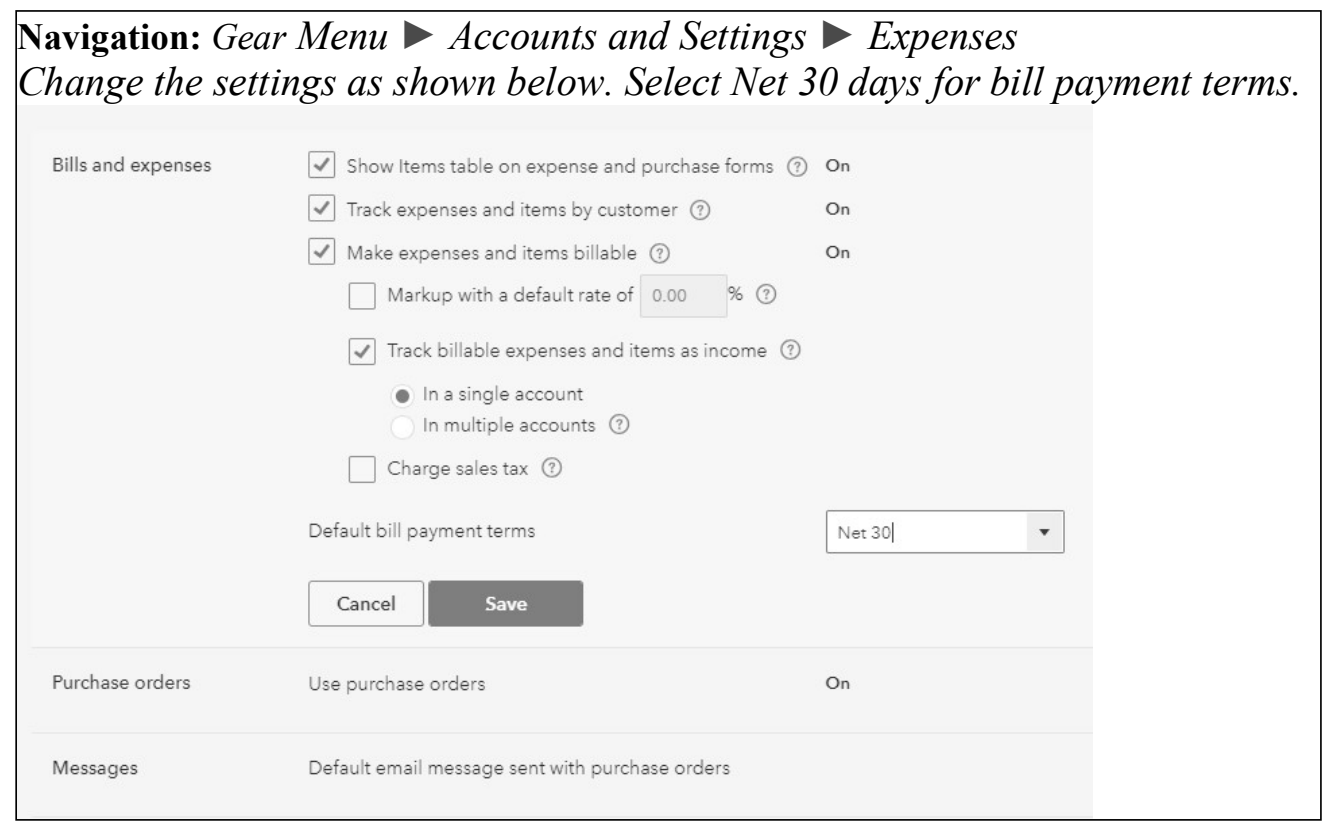

Figure 2. Company Configuration-Net 30 days for bill payment term

Adding accounts to the default chart of accounts is also very simple. The process for creating a bank account is shown in Figure-3 below. 


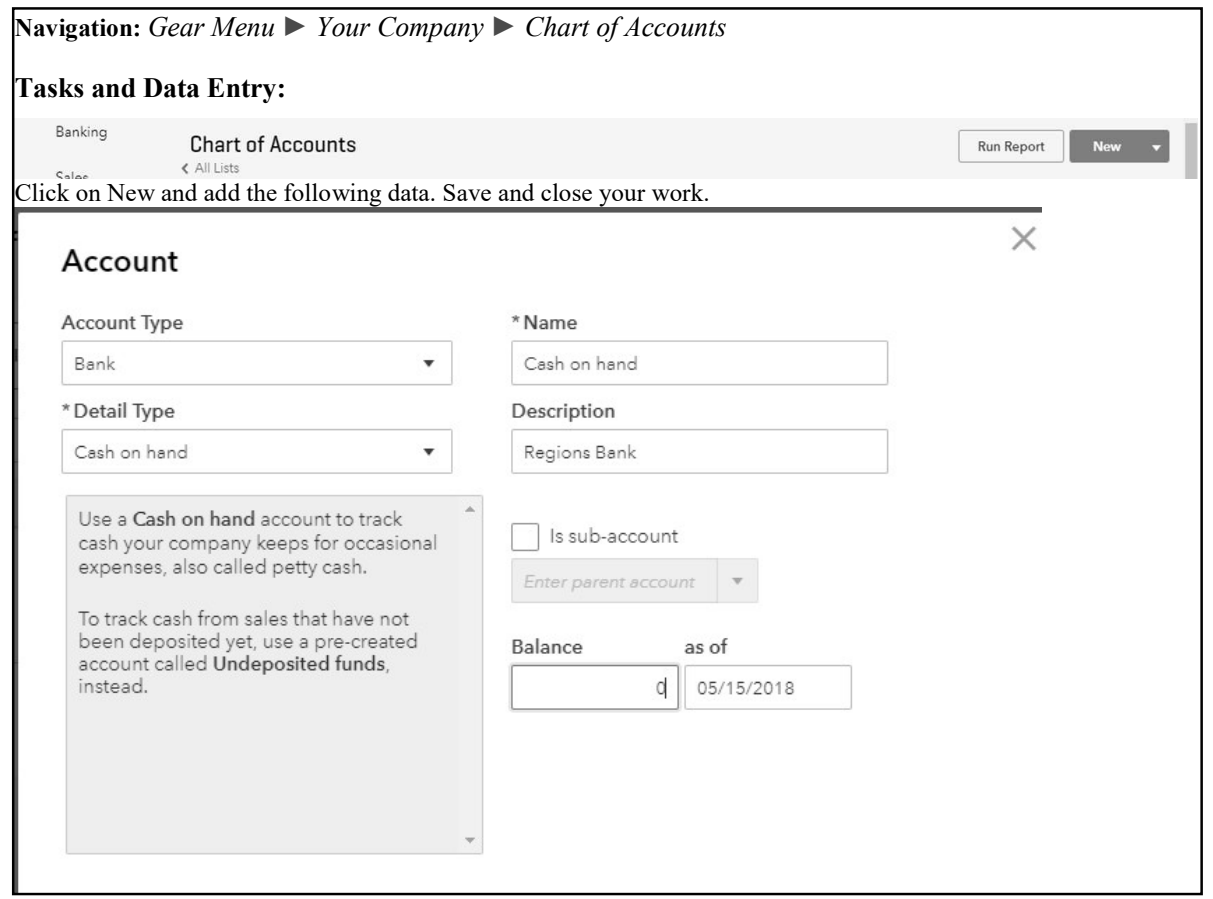

Figure 3. Creating new accounts in COA

Adding Inventory items, Vendors, and Customers are completed on similar data entry screens. The screen for adding inventory items is shown in Figure-4. A user is required to add name, initial quantity on hand (0), and the as of date for all trading goods.

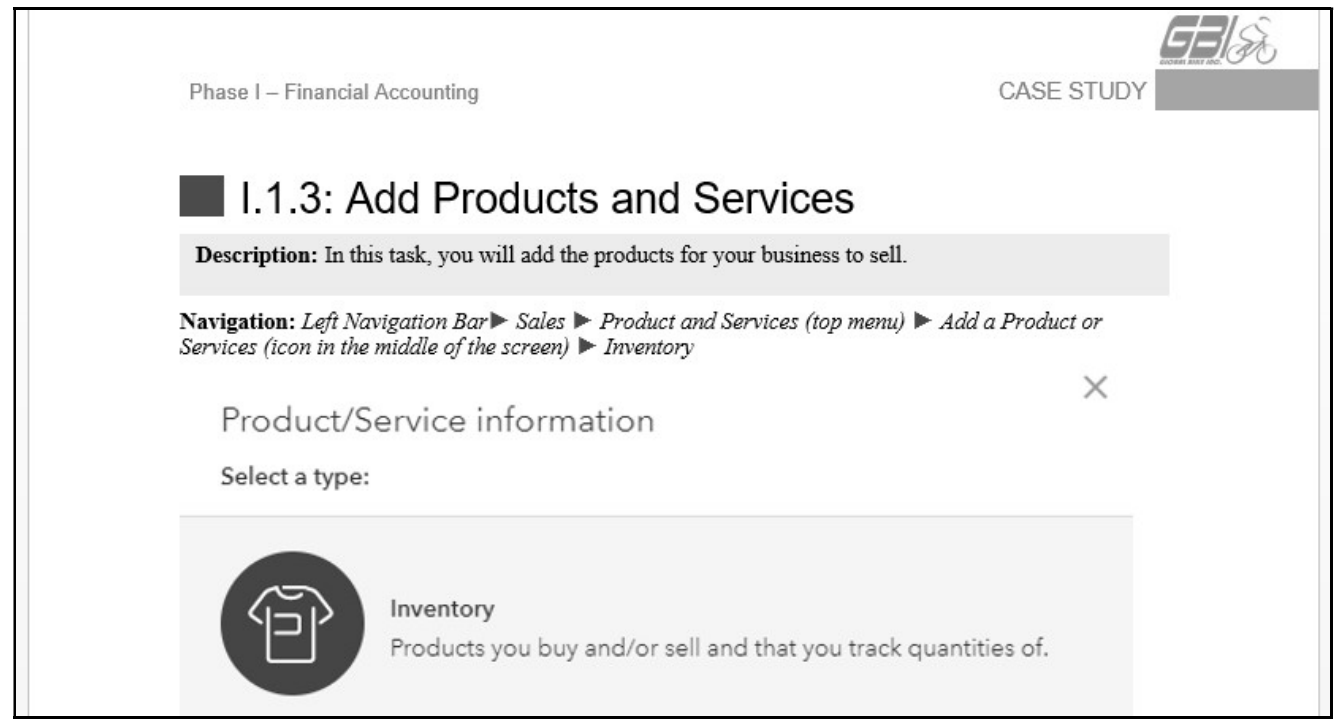

Figure 4. Screen for adding Inventory Items

For vendors and customers the user is required to add the following data items: name, address, and email. For vendors their opening balance also has to be provided. 
After these set of configuration exercises, the user is ready to start the exercises for the ERP processes discussed in Table-2 through Table-4 in the previous section.

\section{BENEFITS OF ERP ON QUICKBOOKS ONLINE PLUS}

QBO Plus is not a pure implementation of ERP as was the case with QuickBooks Accountant. However, as the popular accounting software moved to the SaaS implementation, there was pressure on us to move to QBO Plus. There were distinct advantages that the SaaS implementation offered such as access from multiple types of devices, 24/7 access from any place with internet access, multiple users accessing the system (although not at the same time) etc. The software, despite its limitations, resulted in reinforcing the same concepts of ERP as QuickBooks Accountant. As more features are made available on QBO Plus, we will be able to improve the fulfillment processes to bring it in line with a pure implementation of a traditional ERP product. Our previous study had established that the exercises in QuickBooks helped the students get a better understanding of concepts such as Profit and Loss (P\&L), Balance Sheets, and Inventory Management, as well as the sales and procurement cycle (Hingorani, et al., 2015). The ability of QuickBooks to quickly generate reports on balance sheets, P\&L statements, and Inventory valuation helped in the understanding of the financial aspects of the business. The students were able to also understand how office supplies can be expensed in the P\&L statement.

\section{SUMMARY}

There is an increased demand from students for software skill sets that are being used in industry. Most software vendors have educational programs that allow students and faculty free access to software. However many vendor supplied programs have steep learning curves and require students to go through tutorials and other learning materials that requires weeks of instructions. This paper presents a case study of introducing QBO in a class on ERP configuration.

A QBO tutorial was developed that modeled the ERP configuration and process execution of SAP. A previous implementation of QuickBooks on a desktop was very successful and was a required component of the class. The availability of QBO Plus at no cost motivated the college to create a new tutorial using QBO. The 31-page tutorial can be completed by most students within 2 hours, although some can complete it in less than an hour. The tutorial requires the students to print balance sheets, income statements, and inventory details at various stages and provides students with a better understanding of Accounts Receivable, Accounts Payable, and expensing office supplies, which are key accounting concepts. Although QBO Plus is not an ideal implementation of an ERP software, it is easy to use, covers the financial accounting, procurement and sales cycle and provides students with skill sets that are valued in industry.

\section{REFERENCES}

Antonucci, Y. L., Corbitt, G., Stewart, G., \& Harris, A. L. (2004). Enterprise systems education: Where are we? Where are we going? Journal of Information Systems Education, 15(3), 227-234.

Brooks, S. (2017). Is Intuit Leaving Others in Their Dust? Enterprise Times. May 24, 2017. Accessed May $16,2018$. https://www.enterprisetimes.co.uk/2017/05/24/intuit-powered-up-by-quickbooks-sales/.

Dignan, L. (2015, December 04). QuickBooks Enterprise: The forgotten mid-market ERP player. Retrieved from http://www.zdnet.com/article/quickbooks-enterprise-the-forgotten-mid-market-erp-player

SAP AG University Alliance. (2013) Introduction to SAP ERP using Global Bike Inc. 2.11. Available: https://cw.sdn.sap.com/cw/docs/DOC-153068

Hingorani, K., Beasley, B., \& Bradford J. (2015). Enhancing Student Learning of ERP Configuration Through a QuickBooks Tutorial. Issues in Information System, 16(1), 132-141. 


\section{Issues in Information Systems}

Volume 19, Issue 4, pp. 132-139, 2018

Intuit Community. (2017, October 15). Hi is it possible to covert a sales order to a purchase order? Retrieved from https://community.intuit.com/questions/1630362-hi-is-it-possible-to-covert-a-sales-order-to-a-purchaseorder.

Intuit Inc. (2017). Intuit First-quarter Revenue Increased 14 Percent; Led by QuickBooks Online Subscriber Growth of 56 Percent. Retrieved from https://investors.intuit.com/Press-Releases/Press-Release-Details/2017/IntuitFirst-quarter-Revenue-Increased-14-Percent-Led-By-QuickBooks-Online-Subscriber-Growth-of-56Percent/default.aspx

SAPUAP (2013) - New curricula for UAP members: SAP ERP configuration using GBI. (n.d.). Available: http://scn.sap.com/community/uac/blog/2013/01/10/new-curricula-for-uap-members-sap-erp-configurationusing-gbi.

SAP Corporate Fact Sheet. (2018). Retrieved from https://www.sap.com/corporate/en/documents/ 2017/04/4666ecdd-b67c-0010-82c7-eda71af511fa.html

SAP University Alliances. (2018). Retrieved from https://www.sap.com/training-certification/universityalliances.html

Winkelmann, A. \& Leyh, C. (2010). Teaching ERP Systems: A Multi-perspective View on the ERP System Market. Journal of Information Systems Education, 21(2), 233-240. 